\title{
The changing face of acute rheumatic fever
}

\author{
Edwin Besterman ${ }^{1}$
}

Florid acute rheumatic fever with classical, flitting polyarthritis and a high temperature has become a relative rarity in the more economically advanced nations, though it is still seen quite frequently in populations that are materially less prosperous. Whether the prevalence of chronic rheumatic heart disease has declined in a similar manner remains an outstanding question.

Results of recent inquiries into this problem are contradictory: geography, social conditions, and age are factors that influence the findings. In a survey of rheumatic heart disease in Denver parochial schoolchildren, Morton, Huhn, and Litchy (1967) found a prevalence of $\mathrm{I} \cdot 7$ cases per thousand. This mean figure included a range from 0.8 at the age of I0, to 3.I per thousand at the age of 15 . In the higher socio-economic class, the prevalence was half that found in the lower social bracket. Interestingly, the prevalence of rheumatic heart disease without a history of known rheumatic fever was four times commoner in the latter group. Other school surveys carried out since 1960 have shown prevalence rates per thousand ranging from 0.6 in Toronto to $I .8$ in Osaka. In earlier surveys, London in 1937 had the highest figure of 7.7 per thousand, whereas Toronto in 1948 had a prevalence rate of 1.6 per thousand. In their 1967 series, Morton et al. suggest that the prevalence in Denver City Schools would probably be 20-50 per cent higher than their parochial series. Recent reports from Israel show a prevalence in schoolchildren of 0.7 per hundred in Tel-Aviv and Haifa, as compared with $\mathrm{I} \cdot 6$ in Jordan (Davis, I969). However, current estimates of the over-all prevalence of chronic rheumatic heart disease in Sweden put the figure at 1.5 per thousand (Hall, 196I). In a survey of an older population in the United States (Stamler, 1967), a history of rheumatic fever was found in 17.5 per 1 Address: Department of Cardiology, St. Mary's Hospital, London W.2. thousand college students and murmurs of rheumatic heart disease were found in 5.7 per thousand. Over-all, in 1960 it was estimated that $1,200,000$ people were suffering from chronic rheumatic heart disease in America.

In London schoolchildren the annual death rate due to acute rheumatism has been falling over the year's from 67 per million in 1900 to 2 per million in 1965 . In a retrospective study of patients seen between 1930 and I954 at Malmo, Hall (I96I) reported a similar decline in acute mortality, and noted that the incidence of polyarthritis and acute endocarditis also fell. In addition to the diminished severity, the prevalence of rheumatic fever appears to have changed in the past 60 years. It has been notifiable in Denmark since 1900; then, the incidence was 20 per ten thousand whereas it had fallen to 8.3 by I94I. In this country acute rheumatism is only notifiable in certain limited areas. The reported incidence has fallen from 0.05 per cent of the child population in 1948 to 0.014 per cent in I965. It must be realized that such notifications will necessarily be incomplete. In a review of this aspect of diminishing severity, Bywaters (1969) noted that rheumatic fever comprised 5 per cent of the admissions to Guy's in 1914 but by 1952 this figure was reduced to 0.23 per cent.

Stamler (1967) has pointed out that the attack rate of rheumatic fever may be as high as 30 per thousand following a group A streptococcal throat infection. Prophylaxis with penicillin or sulphonamides and early antibiotic treatment of acute infections have changed this picture considerably. Hitchens (1956) studied the decline in notifications of acute rheumatic fever as compared with those of scarlet fever. The actual incidence of scarlet fever diminished from 1926 onwards but the mortality rates changed most noticeably at a later date, falling from 0.47 per hundred cases to 0.12 between the years 1935 and 1942 . Though no consistent relation has been 
shown between the incidence of scarlet fever and that of acute rheumatism, the diminishing crude death rate from scarlet fever corresponds closely to that from acute rheumatic fever (Glover, 1943). This reduction in severity of both diseases can be attributed to a change in the virulence of the streptococcus as well as to improved resistance of the host. Wilson, Lim, and Birch (1958), commenting on this change, pointed out that this improvement started before antibiotic therapy and coincided with improved socio-economic circumstances. The changed pattern of the disease due to the diminishing severity of the initial attack of rheumatic fever was noted in patients admitted to Bellevue Hospital between 1935 and 1958 (Mayer et al., 1963). During this time the incidence of carditis fell from 49.7 to 38.4 per cent and the incidence of residual heart disease in the 1951 to 1958 period fell from 40 to 21 per cent. Massell, Amezcua, and Pelargonio (1964) have also commented on the changing picture of rheumatic fever in the 40 years between I92I and 1960. Their incidence of carditis fell from 70 to 50 per cent and of chorea from 45 to 15 per cent. However, the percentage of admissions aged 17 and older was increased: this increased age of the first attack of rheumatic fever is stressed in several reported series.

The decline in reported frequency of rheumatic fever as well as in mortality from this disease does not necessarily imply a massive reduction in its prevalence. Much of this change could be attributed to diminishing severity of the disease. Necropsy analyses have reported an incidence of rheumatic valve disease varying between $I$ and 6 per cent. Woaler (1958) reported such a study from Bergen between the years $194 \mathrm{I}$ and 1955, when 219 cases of rheumatic heart disease were examined. This was the actual cause of death in only 99 of these 219 cases. This 15-year study showed no reduction in the over-all incidence at necropsy though the clinical severity had diminished. In keeping with this clinical change, was the fact that acute rheumatic pancarditis was not seen in any necropsy in the last half of the period under review. This suggests that subclinical and atypical forms of the disease may exist in larger numbers than realized. Statistics from the whole of Norway quote rheumatic heart disease as the cause of death in 0.94 per cent of deaths, whereas this pathological material suggests that $\mathrm{I} \cdot 8$ per cent of deaths were caused by this condition, and that the actual incidence of rheumatic heart disease in this particular series was 4 per cent.

In view of the changing natural history and the diminishing severity of the disease, criteria for its definition and diagnosis become increasingly difficult to standardize, with consequent problems both of recognition and notification. 'Under reporting' will be accentuated by failure of the patients to consult a doctor if symptoms are very mild. Feinstein (1966) has drawn attention to the changing clinical patterns of this disease and stressed that no single examination or test is adequate. The diagnosis now rests on modifications of the original eclectic criteria laid down by Duckett Jones. However, even these modifications exclude minor illnesses. Improved knowledge on the epidemiology of streptococcal pharyngitis, contrary to earlier belief, has shown that many streptococcal infections are asymptomatic, and conversely that many sore throats are due to causes other than the streptococcus. The 3 per cent population progressing to rheumatic fever is confined to those patients with an exudative pharyngitis. In acute rheumatic fever many patients with arthritis may have a non-migratory monarthritis; arthralgia may also be a presenting sign of rheumatism and carditis can develop without chorea or joint involvement. Feinstein noted prolongation of the pr interval on the electrocardiogram after streptococcal infections, regardless of rheumatic involvement, and deduced that this was a nonspecific and useless criterion of rheumatic activity. In the diagnosis of carditis, careful auscultation is of most value, preferably carried out on repeated occasions by several skilled observers. In his series, Feinstein stressed the diagnostic problems in an 8-year follow-up of 440 patients: residual carditis was present in over 50 per cent of those with initial arthralgia or arthritis and carditis, as opposed to 73 per cent of those with carditis alone initially. In an earlier review (1962) Feinstein and Spagnuolo had pointed out that the term 'rheumatic fever' was losing its diagnostic utility when applied to patients who had neither rheumatism nor fever. They particularly stressed the diagnostic value of demonstrating a preceding group A streptococcal infection. Davis (1969) has also mentioned other significant presenting symptoms including epistaxis, abdominal pain, and 'growing pains'.

Thus, as the picture of acute rheumatic fever becomes less typical, the prevalence of chronic rheumatic heart disease is necessarily going to be measured increasingly by routine medical examinations, rather than by followup of known cases of acute rheumatic fever. Stamler (1967) contrasted the prevalence of rheumatic murmurs in $\mathrm{I} \cdot 3$ Chicago elementary 
schoolchildren with a figure of 3.3 per thousand in older high-school children. In World War II American conscription examinations, 16-18 men per thousand were found to have rheumatic murmurs. In an analysis of 96,000 Americans rejected for military service for reasons of cardiovascular disease, 50 per cent had rheumatic murmurs. These were later reexamined by a panel of cardiologists who confirmed the diagnosis in 83 per cent. These figures from the second war were contrasted by RuDusky (1963) with a current study, again in a dominantly male population of army recruits. Of these, only 0.88 per cent were rejected for reasons of rheumatic heart disease as compared with 2.4 per cent in I94I. When murmurs were analysed in the current series, 80 per cent were classed as functional, 18 per cent as rheumatic, and 3 per cent as congenital. By contrast, in 1943, only 35 per cent had been labelled functional, whereas 60 per cent were considered rheumatic and 4.4 per cent congenital. This suggests a 63 per cent decrease in rheumatic heart disease and a 37 per cent decrease in congenital heart disease. In comparing some of these retrospective examinations of previous years with the more recent ones, it must be borne in mind that knowledge of congenital heart disease in the earlier years and methods for evaluating benign murmurs were far less well defined than today; the proportional increase in congenital heart disease and decrease in rheumatic heart disease must in some part be due to these factors.

Lee (1958) compared British school medical findings in men who were later found to have murmurs on examination for military service. Only 60 per cent of the latter had been recognized at school, and these were all severe lesions. This difference between school and Service examinations was also found in other fields. An analysis of epilepsy showed a school figure of I.2 per thousand whereas the Military reported it in 5.4 . In routine medical examinations, Lee stressed the lack of normal doctor/patient confidence and relationship. Another interesting aspect of routine medical examinations emerged from a special inquiry conducted into the prevalence of otitis media where an actual incidence of I per cent was found compared to the national average quoted as 0.3 per cent. Smith et al. (1965) carried out a study on Chicago schoolchildren using a heart sound tape and then examining those with positive findings. Estimated corrected prevalence rates for these murmurs showed 3.3 of rheumatic and 2.8 of congenital origin per thousand of this population. However, iatrogenic heart disease was present in
2.I per thousand, and Bergman and Stamm (1967) have stressed the degree of disability arising from 'cardiac nondisease' which they believe is probably a greater problem than that arising from actual heart disease, due to faulty diagnoses on routine examinations.

In an endeavour to overcome the inherent difficulties of diagnosis in large-scale examinations by school medical officers, a Standing Medical Advisory Committee was set up to study rheumatic fever in Scotland by the Scottish Home and Health Department, and this Committee reported in 1967. As a pilot survey, teams of consultant cardiologists examined children from certain schools in two regions. In the Eastern Region, 7 out of the Iro were put down 'for recall as suspect valvular disease'. In fact, neither these, nor a similar sample from the other region were investigated further for a variety of reasons. However, it seems possible that between I and 3 per hundred of these populations might have had a significant murmur, and it is therefore truly remarkable that two of the conclusions published in this Report are: 'it is concluded that a survey of this type does not yield results commensurate with the time, labour and inconvenience expended and also it is further clear that in the sample examined overt cases of rheumatic and congenital heart disease are alike uncommon. There would appear to be no hidden reservoir of undetected cardiac disease in this sample of school leavers'. These are somewhat unexpected deductions in view of both the small sample examined and the results obtained.

With regard to the prevalence of adult chronic rheumatic heart disease, Parkinson reported in 1945 a probable figure of 240,000 for this country. In the past decade, hospital admissions have been fairly constant at 15,000, but the deaths from chronic rheumatic heart disease had fallen from 9,000 in 1948 to 7,000 by 1960 . Certainly the majority of cases with chronic rheumatic heart disease have either minimal or only slight disability, but this change in chronic rheumatic heart disease mortality may likewise reflect a change in the pattern of severity rather than in prevalence. The latter will certainly not be known for some years. Certainly all follow-ups have shown that the more severe the initial attack, the worse the long-term prognosis becomes.

Thus, the effects and benefits of early therapy are still difficult to evaluate, but as the prognosis varies directly with the initial cardiac status, early or late recognition of the presence of acute carditis is bound to affect the subsequent course. In the Joint Report on the natural history of rheumatic fever (Rheu- 
matic Fever Working Party, 1965), after 10 years, in those cases without carditis at the onset of treatment only 6 per cent had murmurs. The relation of satisfactory treatment to subsequent heart disease was first remarked upon by Sibson in 1877: of 24 patients who were treated with adequate rest, only 3 had residual heart disease as opposed to 43 out of 127 who were not so rested.

Thus the available evidence suggests that the severity of both rheumatic fever and of carditis has diminished in the acute attack, associated with altered virulence of the streptococcus, improved social conditions, earlier treatment of streptococcal infection with antibiotics and with long-term antibiotic or sulphonamide prophylaxis in known rheumatic cases. However, there appears to be an increase in the number of 'sub-clinical' cases of rheumatic carditis who do not meet the accepted criteria for diagnosis and pass unrecognized as such. This group of patients may in consequence suffer a higher incidence of residual carditis through lack of early treatment when compared with 'classical' rheumatic fever, recognized and treated immediately. Thus, the present prevalence of chronic rheumatic heart disease remains uncertain but may not be diminished as much as the reduced prevalence of florid acute rheumatic fever would suggest. More probably, both conditions, acute and chronic rheumatic heart disease, will be found to have shown some reduction in prevalence but with a greater reduction in severity.

\section{References}

Bergman, A. B., and Stamm, S. J. (1967). The morbidity of cardiac nondisease in school children. New England fournal of Medicine, 276, 1008.

Bywaters, E. G. L. (1969). Rheumatic fever and chorea In Textbook of the Rheumatic Diseases, 4th ed., p. 200. Ed. by W. S. C. Copeman. E. and S. Livingstone, Edinburgh.

Davis, E. (1969). Rheumatic Fever. Charles C. Thomas, Springfield, Illinois.

Feinstein, A. R. (1966). The natural histories of acute rheumatic fever. Bulletin on Rheumatic Diseases, 17, 423.

, and Spagnuolo, M. (1962). The clinical patterns of acute rheumatic fever, a reappraisal. Medicine, 41, 279.

Glover, J. A. (1943). War-time decline of acute rheumatism. Lancet, 2, $5 \mathrm{I}$.

Hall, P. (I96r). On the prognosis and natural history of acute rheumatic fever and rheumatic heart disease. Acta Medica Scandinavica, Suppl. 362.

Hitchens, R. A. N. (1956). Decline of acute rheumatism. Annals of the Rheumatic Diseases, 15, 160.

Lee, J. A. H. (1958). The effectiveness of routine examination of schoolchildren. British Medical fournal, $1,573$.

Massell, B. F., Amezcua, F., and Pelargonio, S. (1964). Evolving picture of rheumatic fever. Data from 40 years at the House of the Good Samaritan. Fournal of the American Medical Association, 188, 287.

Mayer, F. E., Doyle, E. F., Herrera, L., and Brownell, K. D. (I963). Declining severity of first attack of rheumatic fever. American fournal of Diseases of Children, 105, 146.

Morton, W. E., Huhn, L. A., and Litchy, J. A. (1967). Rheumatic heart disease epidemiology. Observations in 17,366 Denver schoolchildren. Fournal of the American Medical Association, 199, 879.

Parkinson, J. (1945). Rheumatic fever and heart disease. Lancet, 2, 657.

Rheumatic Fever Working Party, M.R.C. and American Heart Association (1965). Natural history of rheumatic fever and rheumatic heart disease. Ten-year report of a co-operative clinical trial of A.C.T.H., cortisone, and aspirin. British Medical fournal, 2, 607.

RuDusky, B. M. (1963). Heart murmurs in youths of military age. fournal of the American Medical Association, 185, 1004.

Scottish Home and Health Dept., Standing Medical Advisory Committee (1967). Rheumatic Fever in Scotland. H.M.S.O., Edinburgh.

Sibson, F. (1877). In A System of Medicine, Vol. 4, p. 526. Ed. by J. R. Reynolds. Macmillan, London.

Smith, J. M., Stamler, J., Miller, R. A., Paul, M. H., Abrams, L., Restivo, R. M., and deBoer, L. (1965). The detection of heart disease in children. Circulation, 32, 966.

Stamler, J. (1967). Lectures on Preventive Cardiology. Grune and Stratton, New York.

Wilson, M. G., Lim, W. N., and Birch, A. M. (1958). The decline of rheumatic fever. Recurrence rates of rheumatic fever among $\mathbf{7 8 2}$ children for 21 consecutive calendar years (1936-1956). Fournal of Chronic Diseases, 7, 183 .

Woaler, E. (1958). Rheumatic fever and rheumatic heart disease. Acta Medica Scandinavica, 160, 281 and 293. 